\title{
Factors Affecting Rice Farmers' Choice of Formal Seed
}

\author{
Ilangathilaka, K.A.G. ${ }^{*}$ Rupasena, L.P. and Fernando, S. \\ Department of Agricultural Systems, Faculty of Agriculture, Rajarata University of Sri Lanka, \\ Puliyankulama, Sri Lanka \\ *Corresponding Author: \\ Email: anuththara12394@gmail.com
}

\begin{abstract}
Stagnation of rice productivity is a major issue in Sri Lanka because expansion of land extent is not possible due to reach of its maximum level. Moreover, it is urgently need to release some rice lands for cultivation of non-rice crops to meet their demand. Among other factor seed quality greatly influences on rice productivity. Despite the seeds supplied through formal sources such as government and private seed producers are certified for their quality, use of uncertified seeds sourced from informal sources such as farmer-saved seeds which are not certified has been a major problem resulting low productivity. Understanding how farmers choose between formal and informal seed sources is important to promote the use of certified quality seeds among farmers to enhance the productivity. Therefore, this study aims to identify the factors that determine the choice of formal seeds. A total of randomly selected 59 rice farmers in Nachchaduwa settlement of Anuradhapura district was interviewed using a pretested questionnaire. Tabular analysis and binary logistic regression were used to analyze the data. The tabular analysis showed that a $43 \%$ of the sampled farmers used informal seeds due to the unavailability of formal seeds in the farming communities. The price of seeds $(p<0.05)$ and the distance to the source $(p<0.05)$ from the farmer's dwelling have significantly and positively affected the choice of formal seeds over informal seeds. Farmers are more likely to travel far in searching and pay more for formal seeds. This type of behavior reflects the quality consciousness of farmers. To improve the uptake the access to formal rice seeds needs to be increased. Since private or government suppliers of formal seeds are less available in the settlement, individuals and farmer organizations should be incentivized to produce certified formal seeds.
\end{abstract}

KEYWORDS: Formal seed, Informal seed, Seed quality

\section{Introduction}

The average productivity of rice per hectare stagnated around $4.5 \mathrm{mt}$ during the period 2010-2019 in Sri Lanka (Department of Census and Statistics, 2020). The country has no room to expand land further for increasing rice production to meet the demand resulting from population increase. It is also necessary to release some low lands for the cultivation of non-rice crops which are increasing in demand as a result of diversification of food diet (Guei et al., 2011). In this context, Sri Lankan rice policy in the future should focus on productivity enhancement and releasing unproductive low lands for the cultivation of none rice crops. 
There is a possibility to increase productivity under the existing technology because most rice varieties are not achieving their potential yield. Actual yields are only about 4 to 6 $\mathrm{mt} / \mathrm{ha}$ compared with a potential of $10 \mathrm{to} 11 \mathrm{mt} / \mathrm{ha}$ (Department of Census and Statistics, 2020).

Conceptually, the rice productivity is affected by biophysical, management, socioeconomic, institutional, and technology transfer and linkages (Food and Agriculture Organization, 2004; Senevirathna et al., 2008; Firdaus and Natawidjaja, 2010). As a biophysical factor, quality seed has been identified as a major determinant of rice productivity (Diaz et al., 2000; Darmasena et al., 2015; Department of Agriculture, 2017). Yield can be increased by 5-20\% by using quality seed (Dhanapala, 2000; Anh and Pinners, 2003; Senevirathna et al., 2008; Guei et al., 2011).

The quality of the seed rice mainly depends on the source of production (Asea et al., 2010). Both formal and informal sources are involved in rice seed production and distribution in Sri Lanka. Formal seeds (seeds supplied through the formal sources) is produced under the direct supervision of the seeds certification service of the Department of Agriculture, Sri Lanka, and assured for their quality. Seed certification service inspects the production process and certifies that a sack of seed contains what it says on the label and that the seed was produced, inspected, and graded in accordance with the requirements of the certification system (Seed Certification and Plant Protection Center, 2021). Seed certification service ensures that seed is produced, multiplied, and marketed according to predetermined standards and systems while maintaining the genetic integrity of the seed (Seed Certification and Plant Protection Center, 2021).

There have been $80-85 \%$ of rice farmers in Sri Lanka who used seeds obtained from informal sources by 2008 (Senevirathna et al., 2008). Though not in that magnitude, even today, a large number of rice farmers depends on informal seed. Such farmers use own saved seed from their previous cultivation or seed borrowed from neighboring farmers. But the quality of seeds supplied from such informal sources is very low. For instance, the average germination percentage and vigor of farmers' saved seeds of different rice varieties was significantly lower than the formal certified seeds (Doullah et al., 2000; Rahman et al., 2002; Ravindra et al., 2014). Productivity of informally supplied seeds such as farmer saved seeds was also significantly low compared to the formal seeds (Asiedu et al., 2007). Use of informal seeds has also reduced the crop yield, farmers' income, and increased the likelihood of crop failure. Therefore, the promotion of the use of formal seeds among farmers is important to improve rice productivity, ensure product quality, improve farmers' income, encourage formal seeds producers, and sustenance of seed businesses. According to Almekinders, (2000) farmers intend to use informal seeds due to low availability of formal seeds, high cost of formal seeds, high cost of inputs, literacy, and lack of awareness. On the other hand, according to Kotler et al., (2008) decision-making process of individuals involve identifying their needs, gathering information, evaluating alternatives, and then make their decision. Accordingly, farmers' decision to choose formal seeds may have influenced by economic, psychological, environmental social, and cultural factors (Doullah et al., 2000; Rahman et al., 2002; Ravindra et al., 2014). 
There are many studies about the importance of using formal seeds and yield comparison between formal and informal seeds. However, there is limited empirical information on the key factors that explain the use or non-use of formal seeds in Sri Lanka. Therefore, this study aims to identify and evaluate the factors that determine the use of formal seeds by the rice farmers in Nachchaduwa settlement scheme of Anuradhapura district of Sri Lanka. The findings of this study are timely impotent in promoting the use of formal seeds among rice farmers. Whereby contributing to solving the problems of yield gaps, high cost of production, poor quality of rice and farmers' income. On the other hand, the promotion of the use of formal seeds will support the seed industry and create employment as well.

\section{Methodology}

The study was conducted in Nachchaduwa settlement scheme of Anuradhapura district which is one of the main rice growing settlements in the district. It is located about 15 $\mathrm{km}$ south to the district's capital city, Anuradhapura where both private and public suppliers of seed and other agricultural inputs are available. There is a government seed farm about $25 \mathrm{~km}$ away from the study area. Rice is grown in two main seasons; Yala (May to August) and Maha (September to April) in the study area. Rice is also the main livelihood of the settlers in the settlement. The settlement scheme produces 26,014 mt of rice per year.

The study population comprised of rice farmers in the Nachchaduwa settlement scheme. A sample of 60 rice farmers was selected through a random sampling approach. One respondent was dropped during the checking of data upon finding inconsistency of responses provided and final sample consisted 59 respondents. Primary data related to the Yala seasons were mainly collected from farmers through personal interviews using a pre-tested questionnaire during February and March, 2020. The questionnaire sought information on farmers' profile, rice production, use of formal and informal seeds, contextual information such as distance to main city and availability of seed suppliers in the area, and reasons for using formal or informal seeds.

Both descriptive and inferential statistical techniques were applied to analyze the data. Under descriptive analysis, percentages, frequency distribution tables, and tabular analysis were used to describe the data and to examine the levels of using formal and informal seeds (Hilsbose et al., 2004). Following Abdulqader, (2017) a binary logistic regression analysis was applied to examine the factors that determine the use of formal seeds. Mathematically, logit probability is represented by;

$$
\emptyset\left(Z_{i}\right)=e \frac{Z_{i}}{1+e^{Z_{i}}}=\frac{1}{1+e^{Z_{i}}} \quad-\infty<Z_{i}<\infty
$$

Where; $Z_{i}=\beta X_{i} ; \beta$ is a vector of unknown coefficients; $X_{i}$ is a vector of factors of the $i^{\text {th }}$ farmer; $\varnothing\left(\beta X_{i}\right)$ is the probability that the $i^{\text {th }}$ factor will affect farmer's use of formal seeds Eq. (1). 
The probability that a given factor affects farmer's decision to use seeds from formal sources is the area under the standard normal curve between $-\infty$ and $\beta X_{i}$. The larger the value of $\beta X_{i}$, the more important the factor is in affecting farmer's decisionmaking. The change in $\emptyset\left(\beta X_{i}\right)$ relative to the change in $X_{i}$ is given by:

$$
\frac{\delta \emptyset\left(\beta X_{i}\right)}{\delta X_{i j}}=\left[\frac{\delta \emptyset}{\delta Z_{i}}\right]\left[\frac{\delta Z_{i}}{\delta X_{i j}}\right]=f\left(Z_{i}\right) \beta_{j}
$$

Where; $f\left(Z_{i}\right)$ is the value of density function associated with each value of the underlying $Z_{i}$ index Eq. (2).

Farmers' decision to use formal seeds is influenced by a vector of factors, $X_{i}$, including farmer's demographic, socio-economic, contextual, and technical factors. The logit model was specified as:

Where:

$$
\log \left[\frac{P_{i}}{\left(1-P_{i}\right)}\right]=\beta_{0}+\sum_{i j=1}^{n k} \beta X_{i j}+\varepsilon_{i}
$$

$\begin{array}{ll}P_{i} & : \text { Probability that a farmer uses formal seeds } \\ \beta_{0} & : \text { Constant } \\ \sum_{i j=1}^{n k} \beta X_{i j} & : \text { Vector of all the factors (explanatory variables) } \\ \beta_{i} & : \text { Parameters of the factors, and } \\ \varepsilon_{i} & : \text { Random error term }\end{array}$

The empirical model of this study was specified as:

$$
Y=\beta_{0}+\beta_{i} X_{i}+\varepsilon
$$

Where:

$\begin{array}{ll}Y & : \text { Source of seed }(1=\text { formal, } 0=\text { informal }) \\ \mathrm{X}_{\mathrm{i}} & : \text { Monthly household income in }(\mathrm{LKR}) \\ \mathrm{X}_{2} & : \text { Price of seeds }(\mathrm{LKR} / \mathrm{bu}) \\ \mathrm{X}_{3} & : \text { Gender of the farmer }(1=\text { Male, } 0=\text { Female }) \\ \mathrm{X}_{4} & : \text { Prior experience about the sources of seed (years) } \\ \mathrm{X}_{5} & : \text { Distance to the source of seed }(\mathrm{km}) \\ \mathrm{X}_{6} & : \text { Quantity of seed }(\mathrm{kg}) \\ \mathrm{X}_{7} & : \text { Access to extension service }(1=\text { have access, } 0=\text { do not have access) } \\ \beta_{0} & : \text { Intercept } \\ \beta_{i} & : \text { Coefficients of the independent variables, and } \\ \varepsilon & : \text { Error term. }\end{array}$




\section{Results and Discussion}

Following section presents and discusses the results of the study. First, the description of study sample is provided. Second, Sources of seed and reason for non-use of formal rice seed are discussed. Finally factors determining the use of formal rice seeds by farmers are explained.

\section{Description of the Study Sample}

Table 1 provides the characteristics of the sample of rice farmers included in the study. Alam et al., (2011) stated that the socio-economic characteristics of farmers effect on farmer's attitudes and behavior. Therefore, the characteristics of sample farmers who used formal and informal seeds were compared to provide some insights about the similarities and differences between them.

Table 1: Socio-Economic Profile of the Sample by the Type of Seeds used

Variable

\section{Mean}

\begin{tabular}{lcc}
\hline Farming experience (Number of years ) & 23 & 26 \\
Age (Years) & 52 & 49 \\
Education level (Number of years in schooling) & 10 & 10 \\
Monthly income (LKR) & 32,794 & 31,400 \\
Family size (Number of family members) & 3 & 3 \\
Land extent own (Acre) & 2 & 3 \\
\hline
\end{tabular}

Source: Author's survey data, 2020

The results in table 1 indicates that there are no considerable differences among the users of formal and informal seeds. All the farmers are comparable in their age, size of their households, have similar experiences, and education. Their income was also more comparable with only a slight difference. The income of formal seed users was slightly better than those who used informal seed. There was a slight difference in the land size and informal seed users owned slightly a large land holdings.

\section{Sources of Seed and Reason for Non-Use of Formal Rice Seed}

Table 2 shows the sources of formal and informal seeds obtained by the sampled farmers. Amongst different sources of rice seeds, majority of farmers (57\%) obtained formal seeds from government sources $(32 \%)$ and private traders $(25 \%)$. These two sources located at least $15-25 \mathrm{~km}$ away from the farming community. Formal seeds users have traveled relatively a long distance to buy formal seeds compared to informal seed users. Among available sources, majority of the farmer's accessed formal seeds from government sources despite them located far away from the farming community. 
This could be due to the high trust the farmers have on quality of seeds provided by the government sources. A $43 \%$ of farmers on the other hand used informal seeds sourced from neighbor farmers (24\%) and self-production (19\%). Majority of the informal seeds users have used informal seeds due to the lack of availability and reliability of formal seeds within the farming community. Nevertheless, majority of the informal seeds users sourced their seeds from at least neighbor farmers since they were in the opinion that continuous use of own seeds reduce productivity. Moreover, 100\% of the interviewed farmers believed seed quality significantly influence rice productivity.

Table 2: Sources of Seed Accessed by the Sample Farmers

\begin{tabular}{llcc}
\hline & Source of Seed Rice Supply & Number of Farmers & Percentage \\
\hline Formal & Government seed & 19 & 32 \\
& Private trader seed & 15 & 25 \\
\multirow{3}{*}{ Informal } & Neighbor farmer saved seed & 14 & 24 \\
& Self-saved seed & 11 & 19 \\
& Total & 59 & 100 \\
\hline
\end{tabular}

Source: Author's survey data, 2020

\section{Factors Determining the use of Formal Rice Seeds by Farmers}

This section presents and discusses the results of binary logistic regression analysis of data to investigate the factors that determine the use of formal seeds. A summary of the variables included in the model is given in Table 3. Accordingly, the sample of farmers have mean monthly income of LKR 32,797 and paid LKR 1,424 per bushel (about 20.5 $\mathrm{kg}$ ) of rice seed on average. Majority in the sample represented by male farmers. On average, majority of the farmers had about 4 years of experience with their seed source and traveled a distance of about $8 \mathrm{~km}$ to obtain rice seeds. Moreover, farmers have used about 5.5 bushels of seeds on average for their rice fields.

\section{Table 3: Summary Statistics of Respondents}

\begin{tabular}{lccc}
\hline Characteristics & Minimum & Maximum & Mean \\
\hline Monthly household income (LKR) & 15,000 & 60,000 & 32,797 \\
Price of seeds (LKR/bu) & 1,500 & 2,750 & 1,424 \\
Gender of the farmer & 0 & 1 & $1 *$ \\
Prior experience about the source of seed (years) & 1 & 15 & 3 \\
Distance to the source of seeds (km) & 0.25 & 35 & 8 \\
Quantity of seed (kg) & 2 & 18 & 5 \\
$\begin{array}{l}\text { Access to extension service (1=have access, } 0=\text { do } \\
\text { not have access) }\end{array}$ & 0 & 1 & $1 *$
\end{tabular}

Source: Author's survey data, 2020 
The Chi-square value shows that the regression model is significant at $5 \%$ level and best fits to the data. The Nagelkerke's $\mathrm{R}^{2}$ was 0.649 , indicating that the $64 \%$ of the farmers' choice of using formal seeds is explained by the variation of the set of independent variables included in the model (Table 4).

Table 4: Model Summary

\begin{tabular}{lcc}
\hline Log Likelihood & Cox \& Snell R Square & Nagelkerke R Square \\
\hline $41.478 \mathrm{a}$ & 0.48 & 0.65 \\
\hline
\end{tabular}

Table 5 provides the results of the empirical model estimates for the factors that determining the probability that a farmer will use formal seed or not.

Table 5: Logistic Regression Model Estimates Formal Rice Seed by Farmer

\begin{tabular}{lccc}
\hline Variable & Coefficient & Std. Error & Prob. \\
\hline Constant & -4.83 & 2.97 & 0.11 \\
Monthly household income $(\mathrm{LKR})$ & 0.00 & 0.00 & 0.68 \\
Price of seeds $(\mathrm{LKR} / \mathrm{kg})$ & $3 * 10^{-3}$ & 0.00 & $0.03^{* * *}$ \\
Gender of the farmer $(1=$ male, $0=$ female) & -0.79 & 0.97 & 0.42 \\
Prior experience about the source of seed (years) & -0.08 & 0.10 & 0.44 \\
Distance to the source of seeds $(\mathrm{km})$ & 0.18 & 0.08 & $0.02^{* * *}$ \\
Quantity of seed $(\mathrm{kg})$ & -0.19 & 0.13 & 0.15 \\
Access to extension service $(1=$ have access, $0=$ do not & -2.17 & 1.48 & 0.14 \\
have access) & & &
\end{tabular}

Note: ${ }^{* *}$ Significant at $10 \%,{ }^{* * *}$ Significant at $5 \%,{ }^{*}$ Significant at $1 \%$

According to the results, the main factors which significantly affect the probability of use of formal or informal seeds were the price of seeds and distance to the source of seeds. Price of seed had a positive effect on the probability of use of formal seeds at the $5 \%$ significant level. The positive signs of price of seeds in this study also suggest that farmers are more quality conscious rather than price conscious in purchasing formal seed that are of high quality. Quality consciousness is the awareness of high-quality products, and the desire to make a perfect choice when making a purchasing decision. Quality conscious farmers have specific ideas about the best products and the consistent look of these products in terms of their quality (Kim et al., 2002).

Although the expected sign is negative distance to the seed source, it had a positive effect on the probability of use of formal seeds at the $5 \%$ significant level. Most of the literature mentions that there is a negative relationship between distance to buying source and purchasing decision (Liu et al., 2020). However, McKenna and Bargh (2000) found that physical distance is not important in decision making. 
There is a positive relationship because those farmers identified as quality conscious buyers and they thoroughly depend on the quality of the rice seed because $100 \%$ of interviewed farmers believed there is a strong positive relationship between seed quality and rice productivity. Key personnel interviews found that formal seed sources are located in distance areas. For instance the formal source of the DOA is located in 25 kilometers away from the study area (Mahaelukpallama) which is the longest one.

\section{Conclusion and Policy Implications}

Although all the farmers interviewed were aware of formal rice seeds, only $57 \%$ of them used it. The reason for non-use was found to be the unavailability and reliability of formal seeds in the farming community. Also, farmers were willing to buy quality seeds even at a higher price from distant places away from the farming community. Accordingly, it can be concluded that farmers are quality conscious than price-conscious and willingness to pay for quality rice seeds is high suggesting a higher market potential for quality seeds. Farmers used to travel far and pay even a higher price since formal seeds are not available within the farming community. It is necessary therefore to take measures to make quality seed accessible and reliable to the farmers. Attention should be paid to increase the sources of formal seed by enhancing production of formal seeds at farm level through registered farmers and farmer organizations. Because, production of formal seeds by the private sector and the government has not expanded to the required level. Also, it is recommended to enhance the quality of the informal (farmer saved seed) through promotion of self-seeds production programs.

\section{References}

Abdulqader, Q. (2017). Applying the Binary Logistic Regression Analysis on The Medical Data. Science Journal of University of Zakho, 5, 330. 10.25271/2017.5.4.388.

Alam, M., Siwar, C., Talib, B., and Toriman, M. (2011). The relationships between the socio-economic profile of farmers and paddy productivity in north-west selangor, malaysia. Asia-pacific development journal, 18, 161-173. 10.18356/0d668276-en.

Almekinders, C. (2000). The importance of informal seed sector and its relation with the legislative framework. GTZ-Eschborn.

Anh, T., and Pinners, E. (2003). Good seed from the informal rice seed sector a study on the local rice seed sector in northern Vietnam. 1-16.

Asea, G., Geoffrey, O., Anthony, P. N., and Kimani, K. D. (2010). Quality rice seed production manual. 86.

Asiedu, E. A., Asante, R., Sallah, P. Y., Baduon, A., and Avah, E. (2007). Effects of farmers \'seed source on maize seed quality and crop productivity. Ghana Journal of agricultural science, 40(1), 105-111.

Darmasena, H., Wijesinghe, P., and Wijesinghe, R. (2015). Technical Efficiency of Paddy Farming in Low Country Wet Zone Research Report No: 186 May 2015 Hector Kobbekaduwa Agrarian Research and Training Institute. 
Department of agriculture. (2017). Annual Report (2017) [online]. www.cbsl.gov.lk/en/publications/economic-and-financial-reports/annualreports/annual-report-2017.

Department of Census and Statistics, Annual Report. (2020) Available from: http://www.statistics.gov.lk/agriculture//Paddy\%20Statistics/PaddyStats.htm[A ccessed:Jan 04, 2020]

Dhanapala, M. P. (2000). Bridging the rice yield gap in Sri Lanka. In M. K.Papademetriou, F.J. Dent, \& E. M. Herath (Eds.), Bridging the rice yield gap in the Asia-Pacific region. 135-146.

Diaz, C.L., Hossain, M., Merca, S., and Mew, T.W. (2000). Seed quality and effect on rice yield: findings from farmer participatory experiments in CentralLuzon, Philippines. Philipp. J. Crop Sci., 23, 111-119.

Doullah, A.U., Hossain, I., Ali, A., Fakir, G.A., and Mathur, S.B. (2000). Comparative effect of seed cleaning, washing, and seed treatment on seedling disease increase and yield of rice. Bangladesh J. Sci. Technol., 3, 17-21.

Firdaus, D., and Natawidjaja, R. (2010). Study of Potential Availability and Need for Quality Paddy Seeds In Supporting Paddy Production / Productivity in West Java. IOP Conference Series: Earth and Environmental Science. 255. 012010. 10.1088/1755-1315/255/1/012010.

Food and agriculture organization (FAO). (2004), state of food and agriculture 20102011. Women in agriculture: closing the gender gap for development, fao, rome.

Guei, R. G., Barra, A., and Silué, D. (2011). Promoting smallholder seed enterprises: Quality seed production of rice, maize, sorghum, and millet in northern Cameroon. International Journal of Agricultural Sustainability, 9(1), 91-99.

Hilsbose, M., and Song, Il-Yeol. (2004). Use of Tabular Analysis Method to Construct UML Sequence Diagrams. 3288. 10.1007/978-3-540-30464-7_55.

Kim, Y.M., and Shim, K.Y. (2002). The influence of Internet shopping mall characteristics and user traits on purchase intent. Irish Marketing Review, 15(2), 2534.

Kotler, P., Armstrong, G., and Wong, V. (2008). Principles of Marketing. Prenctice Hall International: 5th European edition: Essex

Liu, Q., Zhang, X., Huang, S., Zhang, L., and Zhao, Y. (2020). Exploring Consumers' Buying Behavior in a Large Online Promotion Activity: The Role of Psychological Distance and Involvement. Journal of Theoretical and Applied Electronic Commerce Research, 15(1), 66-80. https://doi.org/10.4067/S0718-18762020000100106

McKenna, K.Y.A., and Bargh, J.A. (2000). Plan 9 from Cyberspace: The Implications of the Internet for Personality and Social Psychology. Personality and Social Psychology Review, 4, 57-75.

Rahman, A.J.M.M., Islam, M.K., Mia, M.A.T., Eusuf, H.M, and Elazegui, F.A. (2002). Quality of rice seed in relation to disease development in farmer's field. Bangladesh Journal of Plant Pathology, 18, 71-76. 
Ravindra, K., Anuja, G., Maheshwari, V.K., \& Atwal, S.S., (2014). Health Status of Farmers' Saved Seed of Various Paddy Varieties in Haryana, India. Plant Pathology Journal, 13(3), 186-192.

Seed Certification \& Plant Protection Centre (2021). Retrieved 10 April 2021, from https://www.doa.gov.lk/SCPPC/index.php/en/

Senevirathna, J.G.D.T., Mettananda, K.A. and Bogahawatta, S. (2008). A study on the present status of seed paddy production in Sri Lanka. Annals of Sri Lanka Department of Agriculture, 8, 177-189. 